\title{
A porosity-based Biot model for acoustic waves in snow
}

\author{
Rolf SIDLER \\ Department of Earth Sciences, Simon Fraser University, Burnaby, British Columbia, Canada \\ Correspondence: Rolf Sidler <rsidler@gmail.com>
}

\begin{abstract}
Phase velocities and attenuation in snow cannot be explained by the widely used elastic or viscoelastic models for acoustic wave propagation. Instead, Biot's model of wave propagation in porous materials should be used. However, the application of Biot's model is complicated by the large property space of the underlying porous material. Here constant properties for ice and air, and empirical relationships are used to estimate unknown porous properties from snow porosity. Using this set of equations, phase velocities and plane wave attenuation of shear- and compressional waves are predicted as functions of porosity or density. For light snow the peculiarity was found that the velocity of the first compressional wave is lower than that of the second compressional wave that is commonly referred to as the 'slow' wave. The reversal of the velocities comes with an increase of attenuation for the first compressional wave. This is in line with the common observation that sound is strongly absorbed in light snow. The results have important implications for the use of acoustic waves to evaluate snow properties and to numerically simulate wave propagation in snow.
\end{abstract}

KEYWORDS: seismics, seismology, snow, snow mechanics, snow physics

\section{INTRODUCTION}

The use of acoustics to investigate snow is complicated by the fact that sometimes lower wave velocities can be observed with increasing density of snow (Oura, 1952). This observation is at odds with elastic or viscoelastic wave propagation theory, for which higher velocities are expected for the considerably higher bulk and shear moduli of denser snow. Yet the observed wave velocities can be explained with wave propagation theory for porous materials, where a second compressional wave, also known as the 'slow' wave, is predicted (Johnson, 1982; Smeulders, 2005). Even though the word 'slow' suggests that it is the velocity of the wave that leads to its name it can actually be shown that 'the fast wave travels in the skeleton and the slow wave in the fluid' (Carcione, 2007, p. 275).

Acoustic waves have been used in snow for a variety of applications. Oura (1952), Smith (1969) and Yamada and others (1974) measured acoustic wave velocities and attenuation in field and laboratory environments. Gubler (1977) measured acceleration in the snowpack and air pressure above the snowpack for explosives used in avalanche mitigation operations. Johnson (1982) successfully used Biot's model for wave propagation in porous materials to predict wave velocities in snow. Sommerfeld and Gubler (1983) observed increased acoustic emissions from unstable snowpacks compared to acoustic emissions of stable snowpacks. Mellor (1975) and Shapiro and others (1997) published extensive reviews on snow mechanics including acoustic wave propagation and proposed wave velocity as a potential index property for snow. Amongst others, Buser (1986), Attenborough and Buser (1988), Marco and others (1996, 1998) and Maysenhölder and others (2012) investigated acoustic impedance and attenuation of snow based on the so-called 'rigid-frame' model (Terzaghi, 1923; Zwikker and Kosten, 1947) in which the wave traveling in the pore space is completely decoupled from the wave traveling in the frame of the porous material. Recently, acoustic methods have been used to monitor and spatially locate avalanches (Surinach and others, 2000; Van
Herwijnen and Schweizer, 2011; Lacroix and others, 2012), to estimate the height and sound absorption of snow covering ground (Albert, 2001; Albert and others, 2009, 2013) and to estimate the snow water equivalent of dry snowpacks (Kinar and Pomeroy, 2009). Kapil and others (2014) used metallic waveguides to measure acoustic emissions from deforming snowpacks. The advantage of the rigid-frame model over Biot's model is that it is relatively straightforward to extract tortuosity of the pore space and pore fluid properties from the phase velocities of the slow wave. Applications are widespread and range from nondestructive testing, medical applications and soil characterization to sound absorption (Fellah and others, 2004; Jocker and Smeulders, 2009; Attenborough and others, 2013; Shin and others, 2013).

The rigid-frame model can be deduced from Biot's (1956a, 1962) theory under the assumption that the stiffness of the porous frame is considerably higher than the stiffness of the pore fluid. The rigid-frame model does not account for the interaction between the pore fluid and the porous frame as does Biot's theory. The viscous effects of the pore fluid are approximated with complex moduli in the rigid-frame model. Consequently the rigid-frame model is a phenomenological model. Biot's model, where the viscous friction of the fluid moving relative to the solid frame is causing the observed attenuation, is a physical model instead. Under exclusion of phenomenological attenuation (e.g. complex bulk and shear moduli) the rigid-frame model is not frequency-dependent while Biot's model, due to its explicit treatment of relative fluid motion, is. Especially in light snow and in wet snow, where the frame and the stiffness of the pore fluid are of a comparable order of magnitude, Biot theory is expected to provide better results than the rigidframe model (Hoffman and others, 2012). Also a physical model is to be preferred over a phenomenological model as the results can be compared to complementary measurements and consequently have more predictive power. However, a disadvantage of the application of Biot's model is the large number of properties that have to be known to solve the differential equations. 




Fig. 1. Krief equation (solid line) fitted and compared to dynamic measurements of Young's moduli (circles) from Johnson (1982). Additional measurements from Smith (1969) are indicated with stars. Theoretical values obtained from numerical modeling of microtomography snow structures are indicated with diamonds and triangles for Schneebeli (2004) and Reuter and others (2013), respectively.

While phase velocities obtained with plane wave solutions for Biot's theory tend to correspond relatively well with its measured counterparts, generally the plane wave attenuation cannot be readily compared. The wave attenuation is complicated by the superposition of effects that all lead to a decrease in wave amplitude and are difficult to separate. Plane wave attenuation does not, for example, account for geometrical spreading, that strongly depends on the geometry of the experiment and is present in virtually all physical measurements.

Here I propose a porous snow model as a function of porosity and use it to estimate wave velocities and attenuation of compressional and shear wave modes using plane wave solutions for Biot's (1956a) differential equation of wave propagation in porous materials. I compare the results to measurements from the literature and investigate the sensitivity of the fast and slow compressional waves to individual snow properties, such as specific surface area (SSA).

\section{METHODS}

\subsection{Porous material properties for snow}

An inherent problem when working with Biot-type porous models is the large number of material properties involved. To address this problem, empirical relationships and a priori information are gathered in this subsection to express the porous material as a function of porosity.

Ten properties have to be known to solve Biot's (1956a) differential equations of wave propagation in porous materials, with porosity arguably being the most significant. For the stress-strain relations the fluid bulk modulus $K_{\mathrm{f}}$, the bulk modulus of the frame material $K_{\mathrm{s}}$, the bulk modulus of the matrix $K_{\mathrm{m}}$ and the shear modulus $\mu_{\mathrm{s}}$ have to be known. The equations of motion require the densities of the solid and fluid materials $\rho_{\mathrm{i}}$ and $\rho_{\mathrm{f}}$, respectively, the porosity $\phi$ and the tortuosity $\mathcal{T}$. The energy dissipation due to the motion of the fluid relative to that of the solid is based on Darcy's (1856) law and requires knowledge of the permeability $\kappa$ and viscosity $\eta$ of the pore fluid.

Typical values for Young's modulus of ice, the frame material of snow, are 9.0-9.5 GPa with a Poisson's ratio of \pm 0.3 (Hobbs, 1974; Mellor, 1983; Schulson, 1999). The
Young's modulus $E$ can be converted to bulk modulus $K$ as (Mavko and others, 2009)

$$
K=\frac{E}{3(1-2 \nu)},
$$

where $\nu$ is the Poisson's ratio. The resulting frame bulk modulus $K_{\mathrm{s}}$ for snow is $\sim 10 \mathrm{GPa}$.

For the snow matrix bulk modulus $K_{\mathrm{m}}$, the Krief equation (Garat and others, 1990)

$$
K_{\mathrm{m}}=K_{\mathrm{s}}(1-\phi)^{\frac{4}{(1-\phi)}}
$$

can be parameterized as

$$
K_{\mathrm{m}}=K_{\mathrm{s}}(1-\phi)^{\frac{a}{(b-\phi)}}
$$

and values for $a=30.85$ and $b=7.76$ can be obtained by $a$ least-square fit on the measurements presented by Johnson (1982). The fit has a relative mean square error of $6 \%$. The relative mean square error towards the complete dataset shown here is $19 \%$. The data of Reuter and others (2013), especially, show a higher variation towards the fit.

Most porous materials have a so-called critical porosity $\phi_{\mathrm{c}}$ that separates their acoustic behavior into two distinct domains (Mavko and others, 2009). For porosities lower than $\phi_{\mathrm{c}}$ the solid frame is load-bearing while for porosities higher than $\phi_{c}$ the porous material acts more like a suspension. The Krief equation is often used in rock physics as it combines the two porosity ranges (e.g. Carcione and Picotti, 2006). Krief's equation in the form of Eqn (2) is empirically fitted to shaley sand where the critical porosity is $\phi_{\mathrm{c}} \approx 0.4$. For snow the critical porosity is considerably higher at about $\phi_{\mathrm{c}} \approx 0.8$, which corresponds to highly porous materials like pumice or porous glass. It is therefore not surprising that the values for $a$ and $b$ differ substantially between Krief's equation and its corresponding fit to snow.

In Figure 1 the Young's moduli resulting from Eqn (3) are shown in comparison with measured and theoretical estimates of Young's moduli (Smith, 1969; Johnson, 1982; Schneebeli, 2004; Reuter and others, 2013).

As data are presented for Young's moduli rather than bulk modulus in the literature, the bulk moduli resulting from Eqn (3) are converted to Young's moduli using Eqn (1) and the linear relationship

$$
\nu=0.38-0.36 \phi,
$$

to express the Poisson's ratio, $\nu$, of snow as a function of porosity. Figure 2 shows how this function relates to measurements of Poisson's ratio from Bader (1952), Roch (1948) and Smith (1969).

In combination with the Poisson's ratio, Eqn (3) can also be used to estimate shear moduli of snow, $\mu_{\mathrm{s}}$, as a function of porosity by using the relationship (Mavko and others, 2009)

$$
\mu_{\mathrm{s}}=\frac{3}{2} \frac{K_{\mathrm{m}}(1-2 \nu)}{1+\nu} .
$$

The shear moduli resulting from Eqns (3-5) are shown in Figure 3 and compared to measurements from Johnson (1982) and Smith (1969).

The tortuosity $\mathcal{T}$ describing the 'twisting' of the actual flow path of the pore fluid compared to a straight line can be estimated based on geometrical considerations as

$$
\mathcal{T}=1-s\left(1-\frac{1}{\phi}\right)
$$

where $s$ is the so-called shape factor (Berryman, 1980). For a 


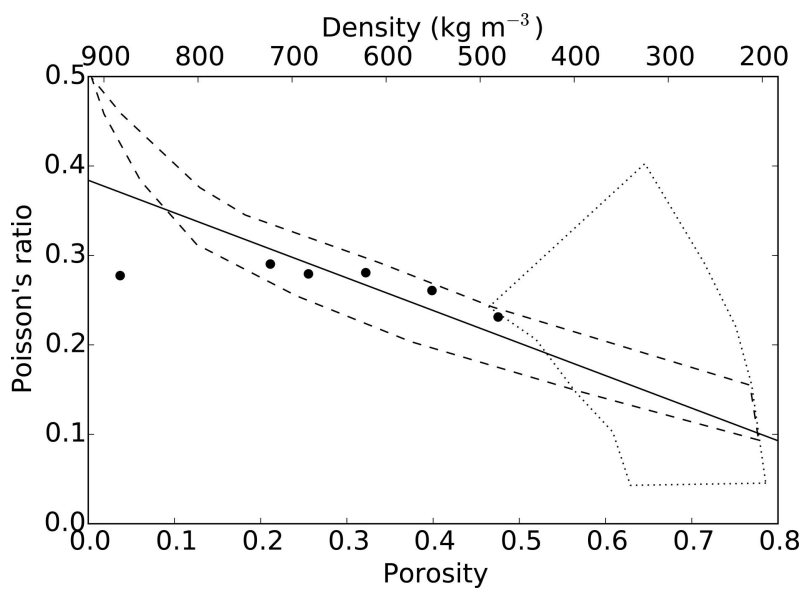

Fig. 2. Poisson's ratio as a function of porosity (solid line) according to Eqn (4) compared to measurements from Bader (1952) (dashed lines), Roch (1948) (dotted lines) and Smith (1969) (circles).

packing of equally sized spheres the shape factor is 0.5 and Eqn (6) reduces to

$$
\mathcal{T}=\frac{1}{2}\left(1+\frac{1}{\phi}\right)
$$

The permeability $\kappa$ is estimated using the Kozeny-Carman relation

$$
\kappa=C \frac{r^{2} \phi^{3}}{(1-\phi)^{2}}
$$

where $C$ is an empirical constant and depends on the material under consideration (Mavko and others, 2009). For sediments the constant is $C_{\text {sediment }}=0.003$ (Mavko and Nur, 1997; Carcione and Picotti, 2006), but for snow it is an order of magnitude larger, $C_{\text {snow }}=0.022$ (Bear, 1972; Calonne and others, 2012). The grain diameter $r$ can be related to the SSA of snow with the relation

$$
r=\frac{3}{\operatorname{SSA} \rho_{\mathrm{i}}},
$$

where $\rho_{\mathrm{i}}$ is the density of ice. Substituting Eqn (9) into Eqn (8) leads to

$$
\kappa=0.2 \frac{\phi^{3}}{(\mathrm{SSA})^{2}(1-\phi)^{2}} .
$$

Due to the compaction and metamorphosis processes inherent to snow it can be assumed that the SSA by itself is a function of porosity (Legagneux and others, 2002; Herbert and others, 2005). Domine and others (2007) use

$$
\mathrm{SSA}=-30.82 \frac{\mathrm{m}^{2}}{\mathrm{~kg}} \ln \left(\rho / \rho_{\mathrm{w}}\right)-20.60 \frac{\mathrm{m}^{2}}{\mathrm{~kg}},
$$

where $\rho_{\mathrm{w}}$ is the density of water, to relate SSA to snow density. For dry snow, density $\rho$ can be obtained from snow with porosity $\phi$ as

$$
\rho=(1-\phi) \rho_{\mathrm{i}} .
$$

Equation (11) yields negative values for the SSA for porosities $\phi \leq 0.44$. Therefore the relationship is used here only for porosities $\phi \geq 0.65$. A constant value for SSA of $15 \mathrm{~m}^{2} \mathrm{~kg}^{-1}$ is used for lower porosities. In this study, Eqn (11) is intended only to reflect an average trend. Where SSA has significant influence on the analysis, high and low end-member values for SSA are also considered.

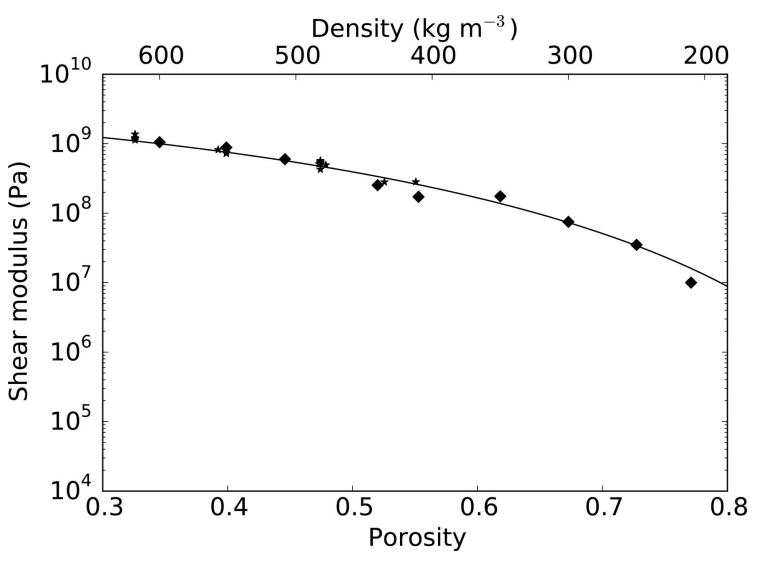

Fig. 3. The shear modulus of snow as a function of porosity (solid line) calculated using Eqns (3-5). Measurements presented by Johnson (1982) and Smith (1969) are indicated with diamonds and stars, respectively.

The density $\rho_{\mathrm{f}}$, viscosity $\eta$ and bulk modulus $K_{\mathrm{f}}$ of air as the pore fluid of snow are assumed to be constant, i.e. independent of temperature and altitude, and are given in Table 1 (Lide, 2005).

\subsection{Phase velocities and plane wave attenuation}

A convenient way to obtain closed form solutions for Biot's (1956b) differential equations is to assume plane wave solutions and substitute these into the differential equations. The complex plane wave modulus is then obtained by solving the resulting dispersion relation (Johnson, 1982; Pride, 2005; Carcione, 2007). As, in the poroelastic case, the dispersion relation is a quadratic equation, there are two roots that correspond to the first and second compressional waves. The phase velocity $V$ and the dimensionless quality factor $Q$, describing the amount of attenuation, can then be obtained from the complex plane wave modulus $V_{c}$ as (O'Connell and Budiansky, 1978)

$$
\begin{aligned}
& V(\omega)=\left[\operatorname{Re}\left(V_{\mathrm{c}}(\omega)^{-1}\right)\right]^{-1}, \\
& Q_{p}(\omega)^{-1}=2 \frac{\operatorname{Im}\left(\mathrm{V}_{\mathrm{c}}(\omega)\right)}{\operatorname{Re}\left(V_{\mathrm{c}}(\omega)\right)},
\end{aligned}
$$

where $\omega$ is the angular frequency.

In this study, the solutions of the dispersion relation resulting from Biot's equations are computed for individual frequencies and porosities. However, if any dissipative effects are ignored and the bulk modulus of the fluid is much smaller than the bulk modulus of the solid matrix it can be shown that the first compressional wave velocity $V_{\infty 1}$ can be expressed as

$$
V_{\infty 1}=\sqrt{\frac{E_{\mathrm{m}}}{\rho-\phi \rho_{\mathrm{f}} / \mathcal{T}^{\prime}}}
$$

Table 1. Pore fluid properties of air (Lide, 2005)

$\begin{array}{lc}\text { Density, } \rho_{\mathrm{f}} & 1.30 \mathrm{~kg} \mathrm{~m}^{-3} \\ \text { Viscosity, } \eta & 1.7 \times 10^{-5} \mathrm{Pas} \\ \text { Bulk modulus, } \kappa_{\mathrm{f}} & 1.42 \times 10^{5} \mathrm{~Pa}\end{array}$




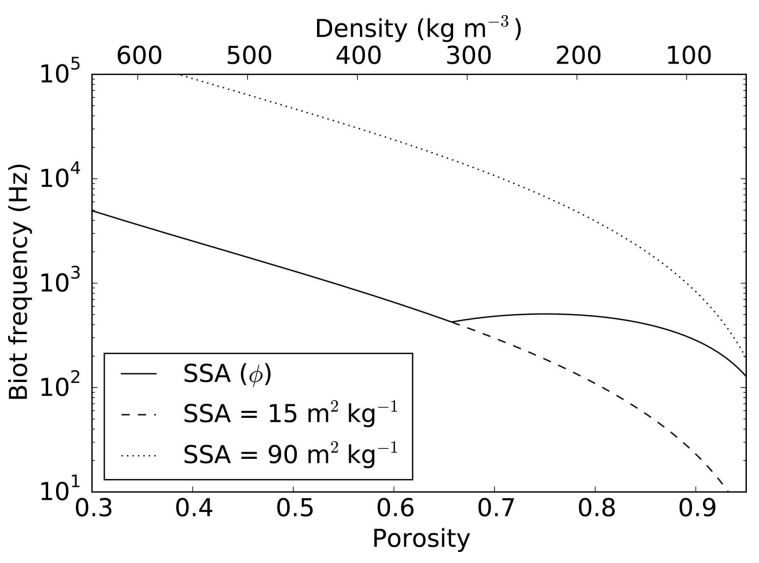

Fig. 4. Biot's characteristic frequency for snow as a function of porosity based on the relations presented in Section 2.1. The solid line corresponds to SSA as a function of porosity (Eqn (11)). The dashed and dotted lines correspond to the end-member values $\mathrm{SSA}=15 \mathrm{~m}^{2} \mathrm{~kg}^{-1}$ and SSA $=90 \mathrm{~m}^{2} \mathrm{~kg}^{-1}$, respectively.

and the second compressional wave velocity $V_{\infty 2}$ as

$$
V_{\infty 2}=\sqrt{\frac{K_{\mathrm{f}}}{\rho_{\mathrm{f}} \mathcal{T}^{\prime}}}
$$

where $E_{\mathrm{m}}=K_{\mathrm{m}}+(4 / 3) \mu_{\mathrm{s}}$ is the ice matrix P-wave modulus (Bourbié and others, 1987, p. 81). Equations (15) and (16) are related to the rigid-frame model and not to Biot's equations considered in this study. These equations are shown here only to illustrate that the first compressional wave travels mainly in the skeleton and the second compressional wave travels mainly in the fluid. Moreover, these expressions also illustrate that the first compressional wave is most sensitive to the properties of the ice matrix, whereas the second compressional wave is sensitive mostly to properties of the pore space and the pore fluid. Note that the compressional wave velocities for the rigid-frame model, Eqns (15) and (16), are not frequency-dependent.

\subsection{Dynamic viscous effects}

The fluid flow in the pores of the material has a different character for lower and higher frequencies (Biot, 1956b). For lower frequencies the flow is of Poisson type where the flow is fastest in the center of a pore and reduces gradually in a parabolic shape towards the outside of the pores. For higher frequencies the importance of inertial forces increases. The fluid in the center of the pores flows all with the same velocity like an ideal fluid, while the fluid at the outside of the pores remains attached to the pore walls. In between the two, the so-called viscous boundary layer forms (Pride, 2005). The transition between low- and highfrequency flow behavior occurs when the viscous boundary layers are smaller than the pore diameter. The frequency at which this transition occurs is called the Biot frequency $f_{\text {Biot }}$ and can be computed as (Carcione, 2007, p. 270)

$$
f_{\text {Biot }}=\frac{\eta \phi}{2 \pi \mathcal{T} \kappa \rho_{\mathrm{f}}} .
$$

Biot's (1956a) theory is considered valid for frequencies up to the Biot frequency. For higher frequencies Johnson and others (1987) introduced a frequency-dependent permeability that accounts for the different flow behavior in the



Fig. 5. Predicted phase velocities for the first compressional wave (solid line) at $1 \mathrm{kHz}$. Measurements from Johnson (1982) and Smith (1969) are indicated with diamonds and crosses, respectively. The dashed and dotted lines are predicted velocities for a $25 \%$ variation of matrix bulk modulus and shear modulus, respectively. The dash-dot line corresponds to a $25 \%$ variation in both.

low- and high-frequency limit and is often referred to as a frequency correction or the JDK model. Figure 4 shows the Biot frequency for snow based on the relationships between porosity and the involved material properties as presented in Section 2.1, where the permeability further depends on the SSA. To illustrate the variability of Biot's frequency due to SSA, the Biot frequency is plotted for Eqn (11) which depends on porosity, and for constant end-member values of SSA $=15 \mathrm{~m}^{2} \mathrm{~kg}^{-1}$ and SSA $=90 \mathrm{~m}^{2} \mathrm{~kg}^{-1}$.

The results shown in this study are evaluated using the frequency correction (Johnson and others, 1987). However, for the first compressional wave there are virtually no differences when the frequency correction is neglected. For the second compressional wave the differences are rather low, except for frequencies in the range of the Biot frequency, where moderate differences can be observed.

\section{RESULTS}

In this section, phase velocities and plane wave attenuation for snow are presented as a function of porosity based on the relationships presented in Section 2.1. Figure 5 shows the predicted phase velocity for the first compressional wave and a frequency of $1 \mathrm{kHz}$ as a function of porosity. The predicted phase velocities are compared to measurements from Smith (1969) and Johnson (1982). In addition, the predicted velocity for an individual and a combined variation of $25 \%$ in bulk and shear modulus is shown. The velocity strongly decreases with increasing porosity, and the variation of bulk and shear modulus for snow of the same porosity is small compared to the change of velocity over the porosity range.

The predicted shear velocities at $1 \mathrm{kHz}$ are compared in Figure 6 to measurements by Johnson (1982) and Yamada and others (1974). Similar to the first compressional wave, the shear velocity strongly decreases with increasing porosity.

The predicted phase velocities of the second compressional wave at $500 \mathrm{~Hz}$ as a function of porosity are shown in Figure 7 and are compared to measurements from Oura (1952) and Johnson (1982). As the pore fluid properties are assumed constant, the phase velocity of the second 


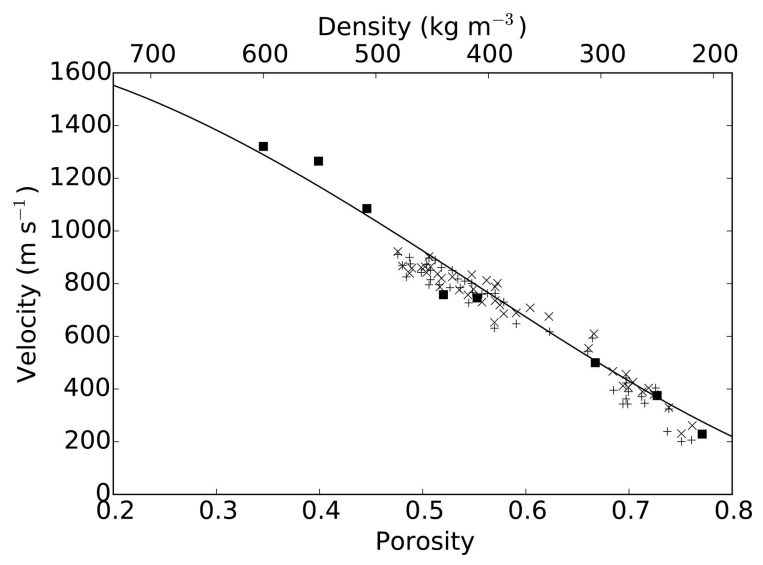

Fig. 6. Predicted shear velocities (solid line) at $1 \mathrm{kHz}$. Squares and crosses correspond to shear wave velocity measurements from Johnson (1982) and Yamada and others (1974), respectively.

compressional wave depends almost exclusively on variations in permeability and tortuosity. Variations in frame bulk modulus and shear modulus have virtually no influence on phase velocity and attenuation of the second compressional wave. The tortuosity has a stronger lever on the phase velocity than the permeability, and $30 \%$ variation in tortuosity leads to larger changes in phase velocity than a $50 \%$ variation in permeability. The phase velocity of the second compressional wave shows little variation with porosity and is mainly sensitive to the geometrical structure of the pore space.

The plane wave attenuation for the first compressional wave as a function of porosity is shown for three different frequencies in Figure 8a. It is striking that the attenuation is orders of magnitude higher for light snow with a porosity


porosity range between $\phi=0.55$ and $\phi=0.8$ cannot be resolved and are therefore shown in Figure $8 \mathrm{~b}$.

Homogeneous Biot-type porous materials are known to have a characteristic peak of attenuation (Geertsma and Smit, 1961; Carcione and Picotti, 2006). In Figure 9 these attenuation peaks are shown for snow of different densities. As in Figure 8, the figure is split into two panels to account for the significant difference of attenuation levels for light and dense snow. Peak attenuation shifts towards lower frequencies, and the attenuation level increases with increasing porosity. The same is true for light snow but with considerably higher attenuation levels. Also the peak attenuation frequencies overlap for a porosity range around $\phi=0.8$.

Phase velocity and attenuation for the second compressional wave obtained with and without using the frequency correction discussed in Section 2.3 are shown in Figure 10. The dynamic viscous effects are relatively small except in the range of Biot's frequency, where the phase velocity shows a moderate difference between the solutions including and neglecting a frequency correction (Johnson and others, 1987). In contrast to the first compressional wave, there is no distinctive difference in attenuation for dense and light snow for the second compressional wave. The sharp bend in phase velocity and attenuation is due to the relationship between porosity and the SSA that was chosen to be constant for $\phi<0.65$ to avoid the negative values resulting from Eqn (11).

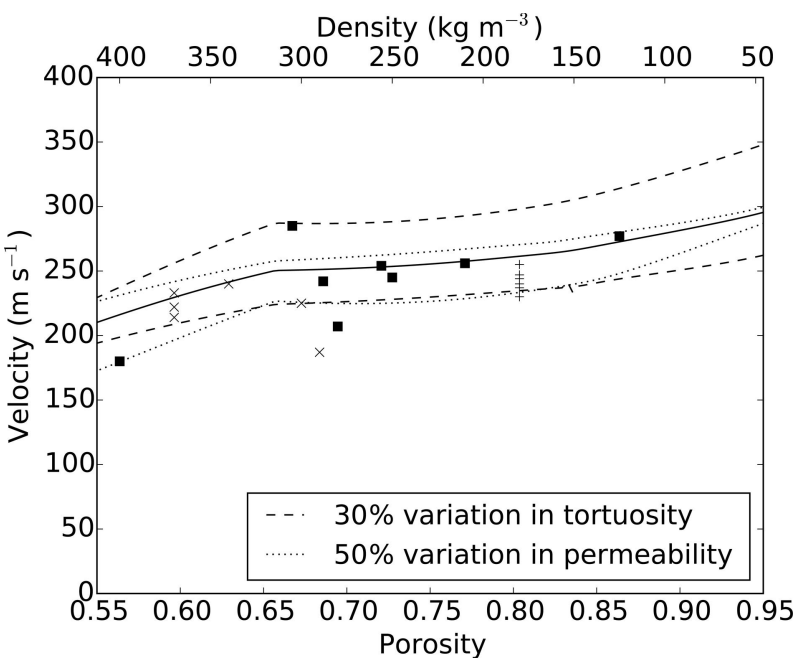

Fig. 7. Predicted phase velocity for the second compressional wave (solid line) at $500 \mathrm{~Hz}$. The dashed and dotted lines correspond to the phase velocities for $30 \%$ variation in tortuosity and $50 \%$ variation in permeability, respectively. Squares represent velocity measurements from Johnson (1982). Crosses correspond to measurements from Oura (1952). Note that an increasing tortuosity decreases the velocity while an increase in permeability increases the velocity of the second compressional wave.

The variation of the phase velocity of the second compressional wave due to changes in SSA is shown in Figure 11. For fixed end-member values of SSA $=15 \mathrm{~m}^{2} \mathrm{~kg}^{-1}$ and SSA $=90 \mathrm{~m}^{2} \mathrm{~kg}^{-1}$ the phase velocity at $500 \mathrm{~Hz}$ is plotted with dashed and dotted lines, respectively. The solid line represents the phase velocities resulting from Eqn (11). The variation is larger for denser snow than for light snow, where permeability is less affected by SSA.

In Figure 12, attenuation for both compressional waves is shown for constant values of SSA $=15 \mathrm{~m}^{2} \mathrm{~kg}^{-1}$ and SSA $=$ $90 \mathrm{~m}^{2} \mathrm{~kg}^{-1}$. Also shown is the attenuation for SSA as a function of porosity according to Eqn (11). The attenuation levels of both compressional waves increase with an increase of SSA.

\section{DISCUSSION}

\subsection{Slow first compressional phase velocity}

Compressional phase velocities as a function of porosity compared to measurements presented by Johnson (1982) and Sommerfeld (1982) are shown in Figure 13. The relations between porosity and the properties of the porous material, especially the strong decrease of matrix bulk modulus with increasing porosity, lead to the peculiarity that the predicted first compressional wave becomes slower than the second compressional wave for light snow with porosity $\phi \approx 0.8$. In most materials, the second compressional wave is considerably slower than the first and is therefore sometimes also called the 'slow' wave. No measurements of the first compressional wave with a lower phase velocity than the second compressional wave have been reported for snow. However, a first compressional wave with lower phase velocity than the second compressional wave has been observed in high-porosity reticulated foam (Attenborough and others, 2012).

From the plane wave solutions it is not immediately clear that the lower compressional velocity in light snow 

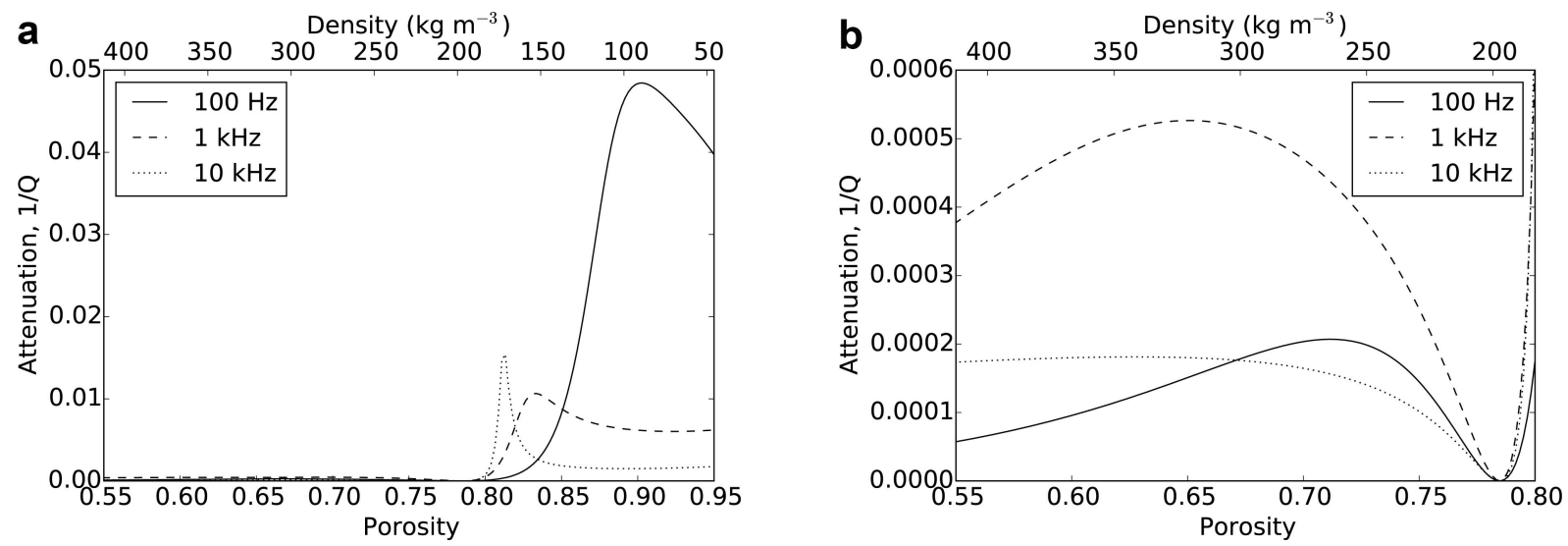

Fig. 8. Predicted attenuation for the first compressional wave as a function of porosity. (b) shows a fragment of (a) for porosities $\phi<0.8$. The attenuation of the first compressional wave is orders of magnitude higher for light snow than for denser snow.
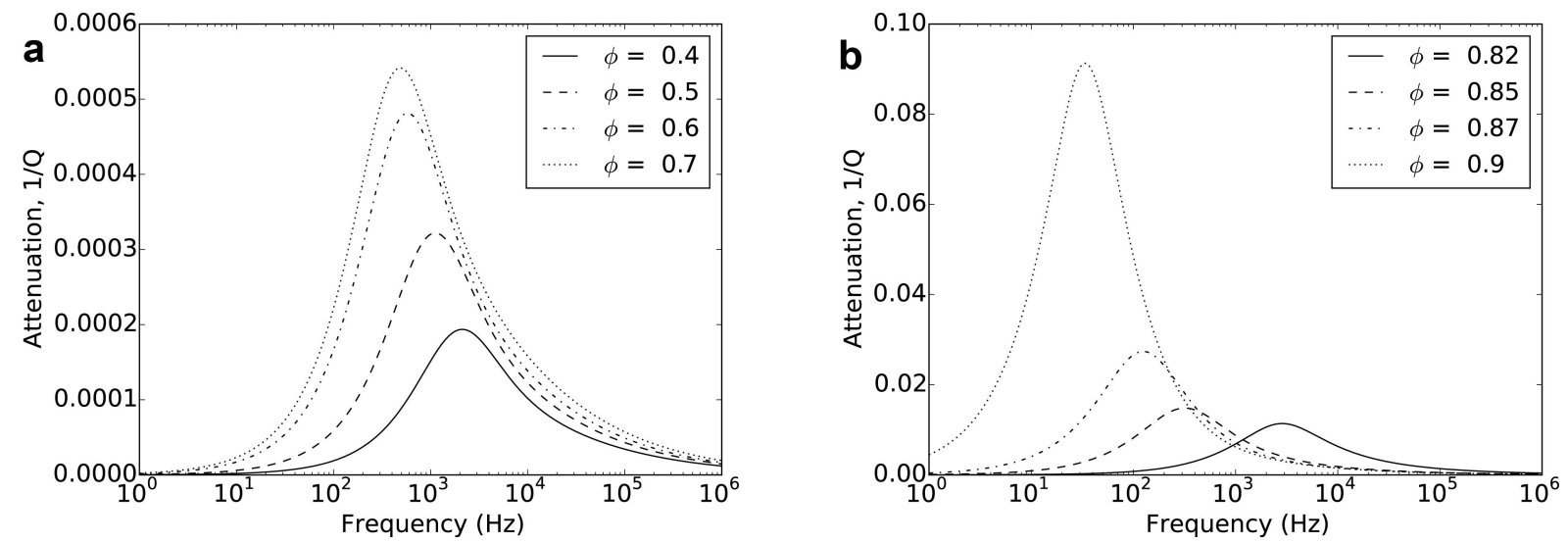

Fig. 9. Frequency-dependent attenuation for the first compressional wave in (a) medium to dense and (b) light snow. The peak of the attenuation shifts toward higher frequencies for denser snow. Note that the amplitude of the attenuation is orders of magnitude larger for light snow with porosity $\phi \widetilde{>} 0.8$.

corresponds to the first compressional wave mode as there are no explicit rules to choose the signs of the square roots. To illustrate that it is indeed the velocity of the first compressional wave that is slower than the phase velocity of the second compressional wave, two numerical simulations solving Biot's equations of wave propagation in poroelastic materials were performed. In the first simulation the homogeneous poroelastic material corresponds to snow with porosity $\phi=0.7$, where the first compressional wave is expected to be faster than the second compressional
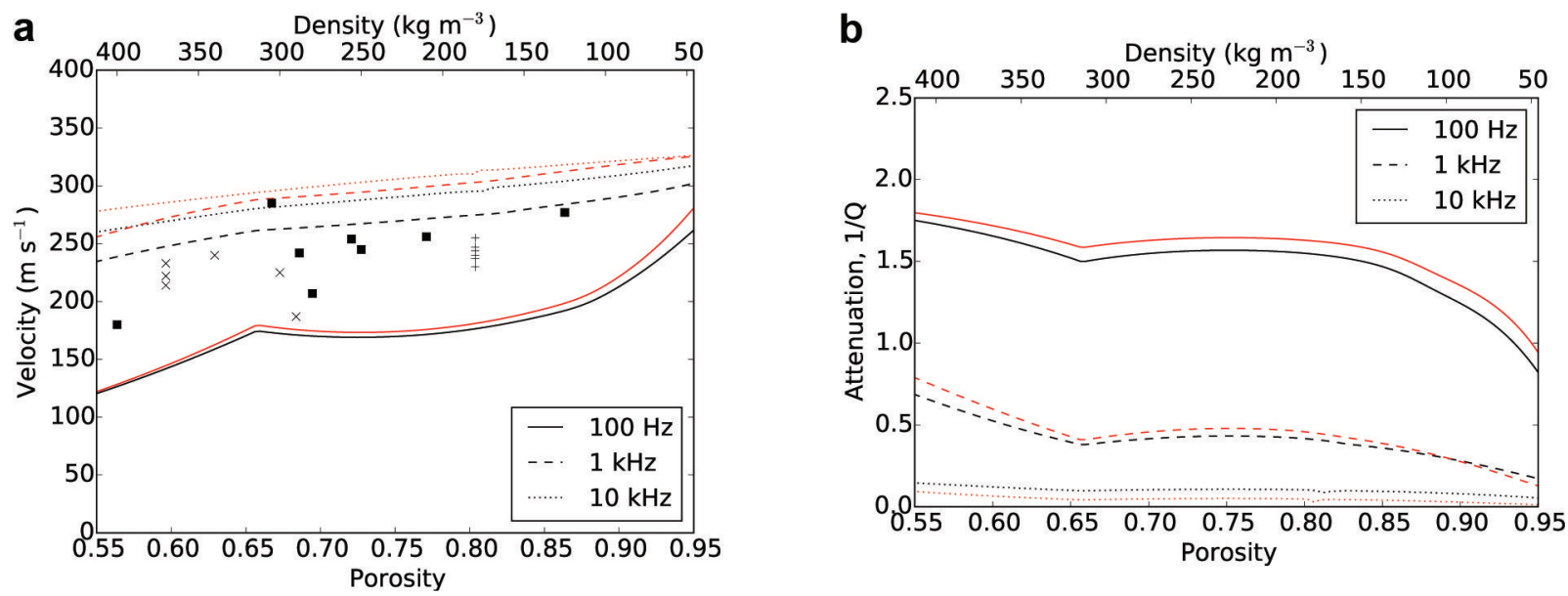

Fig. 10. Phase velocity (a) and attenuation (b) for the second compressional wave for $100 \mathrm{~Hz}, 1 \mathrm{kHz}$ and $10 \mathrm{kHz}$. The black lines correspond to solutions including dynamic viscous effects considered by Johnson and others (1987) while the red lines correspond to solutions of Biot's (1956a) differential equations without correcting these effects. The symbols denote velocity measurements from Oura (1952) and Johnson (1982). 




Fig. 11. Predicted phase velocities for the second compressional wave at $500 \mathrm{~Hz}$ for a SSA as a function of porosity (solid line) and constant values of SSA $=15 \mathrm{~m}^{2} \mathrm{~kg}^{-1}$ (dashed line) and SSA $=$ $90 \mathrm{~m}^{2} \mathrm{~kg}^{-1}$ (dotted line). Squares and crosses correspond to measurements from Johnson (1982) and Oura (1952), respectively.

wave. In the second simulation the porosity of the snow is chosen to be $\phi=0.9$ and the first compressional wave is expected to be slower than the second compressional wave. The relations from Section 2.1 are used to characterize the remaining porous material properties.

For the simulation a pseudo-spectral modeling code was used that solves the acoustic equations in a domain that is located above a second domain where Biot's (1962) equations are solved. Special care is taken to correctly account for the interface between these two domains, and the code was successfully tested against analytical solutions (Sidler and others, 2010). To avoid disagreement of the simulations due to varying parameterization of the source characteristics, which is cumbersome in poroelastic materials, the source was placed at $6.9 \mathrm{~m}$ from the left boundary and $1.46 \mathrm{~m}$ above the air/snow interface at zero vertical distance. The pressure source has a waveform of a Ricker wavelet with a central frequency of $500 \mathrm{~Hz}$. The boundary conditions between the acoustic and the poroelastic domain, which correspond to air and snow, respectively, are assumed to be of the 'open pore' type (Deresiewicz and Skalak, 1963). The field variables of the simulation are the velocity of the solid frame, the velocity of

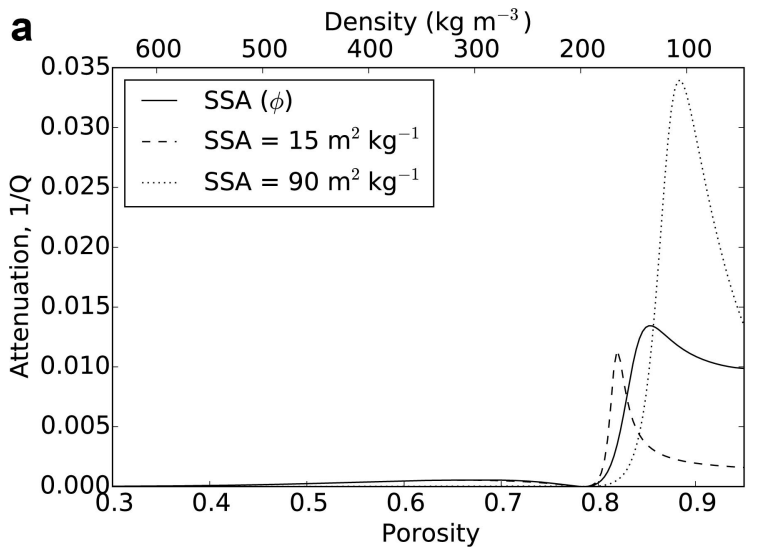

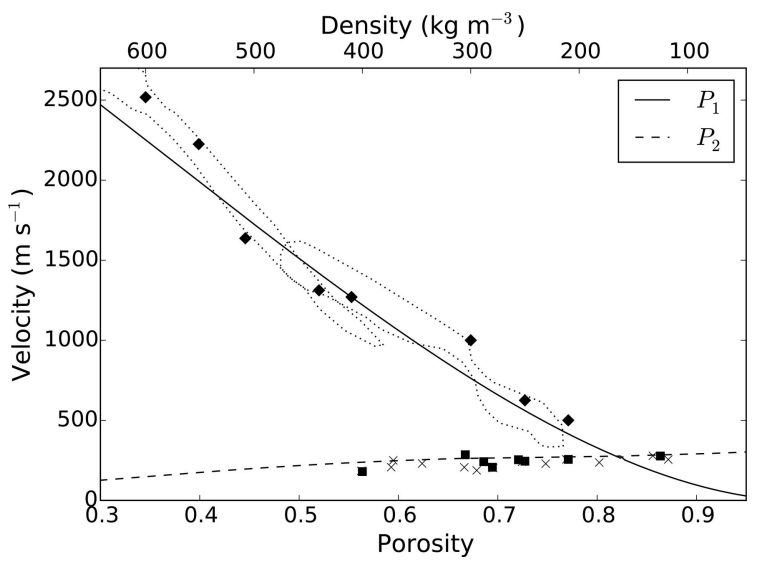

Fig. 13. Predicted velocities for the first (solid line) and second (dashed line) compressional waves as a function of porosity based on empirical relationships for frame bulk and shear modulus, tortuosity and permeability in snow. The dashed lines identify measurements of first compressional waves compiled by Sommerfeld (1982), and diamonds and squares represent wave velocity measurements compiled by Johnson (1982) for compressional waves of the first and second kind, respectively.

the pore fluid relative to that of the solid frame, the stress tensor and the pore pressure. Note that these are particle velocities and should not be confused with the phase velocities discussed before. The first compressional wave has its strongest amplitude in the solid frame velocity field variable, while the second compressional wave has its strongest amplitude in the field variable of the relative fluid velocity.

In Figure 14, snapshots are shown for the two simulations $15.6 \mathrm{~ms}$ after triggering the acoustic source. In the acoustic domain, indicated by positive vertical coordinates, the air pressure is shown in all four panels. For the poroelastic domain, indicated by negative vertical coordinates, Figure 14a and c show the horizontal component of the solid frame velocity field that corresponds to the first compressional wave, and Figure $14 \mathrm{~b}$ and $\mathrm{d}$ show the horizontal component of the relative fluid velocity field that corresponds to the second compressional wave. The simulation for snow with porosity $\phi=0.7$ corresponds to Figure $14 \mathrm{a}$ and $\mathrm{b}$, and the simulation for snow with porosity $\phi=0.9$ corresponds to Figure $14 \mathrm{c}$ and $\mathrm{d}$.

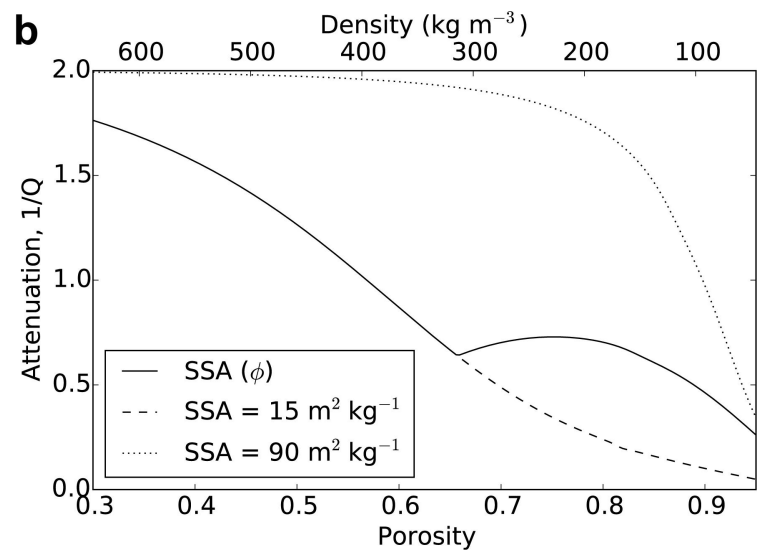

Fig. 12. Predicted attenuation at $500 \mathrm{~Hz}$ for the first (a) and second (b) compressional wave as a function of porosity. The dashed and dotted lines correspond to end-member values of SSA $=15 \mathrm{~m}^{2} \mathrm{~kg}^{-1}$ and SSA $=90 \mathrm{~m}^{2} \mathrm{~kg}^{-1}$, respectively. The solid line corresponds to Eqn (11) and a constant value of SSA $=15 \mathrm{~m}^{2} \mathrm{~kg}^{-1}$ for densities above $315 \mathrm{~kg} \mathrm{~m}^{-3}$. 

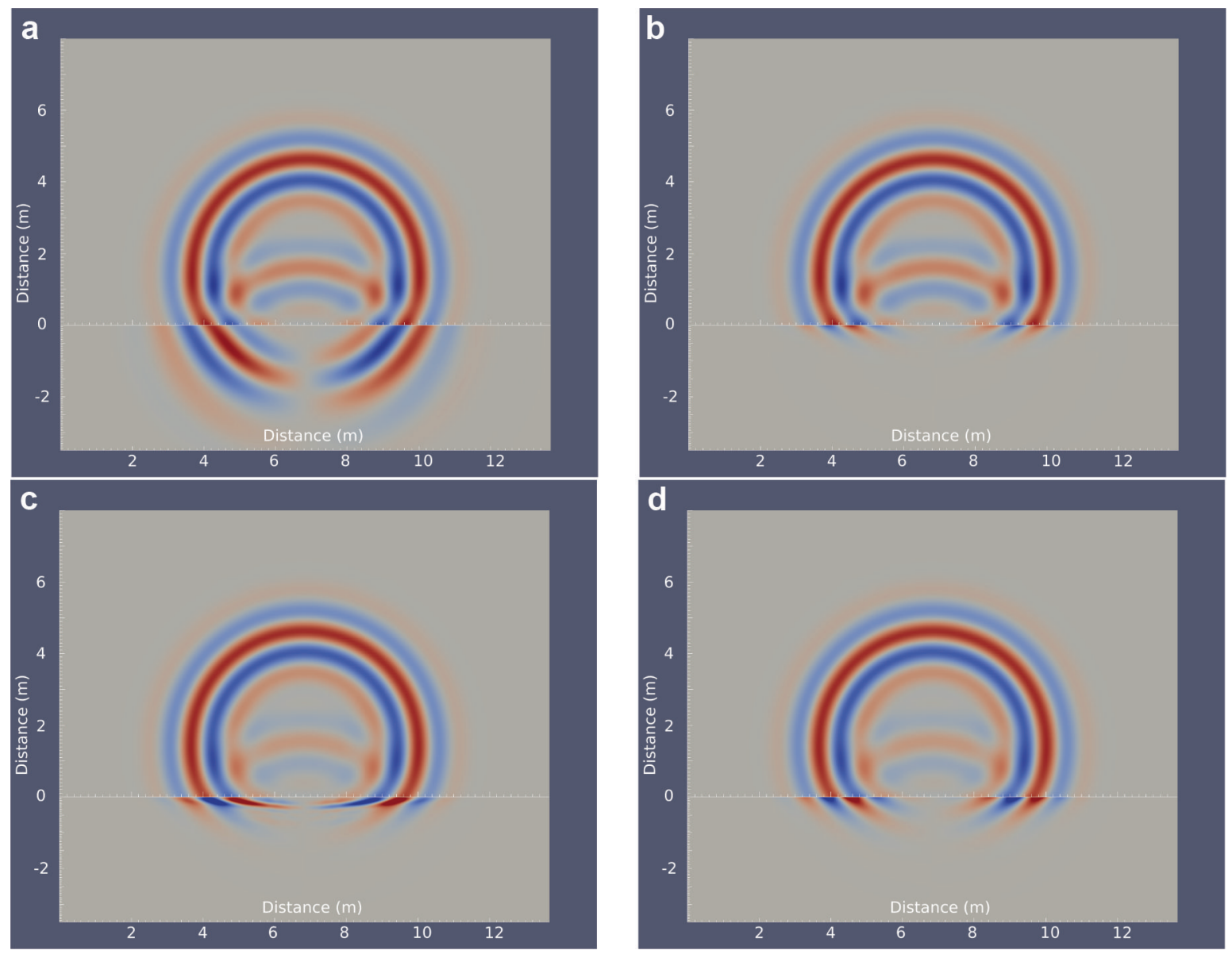

Fig. 14. Snapshots after $15.6 \mathrm{~ms}$ of a numerical simulation of a pressure source in the air over snowpacks with a porosity $(\mathrm{a}, \mathrm{b}) \phi=0.7$ and (c, d) $\phi=0.9$. The horizontal components of $(a, c)$ the velocity of the porous frame and (b, d) the velocity of the pore fluid relative to the porous frame are shown. It can be seen that in the highly porous material $(\phi=0.9)$, the first compressional wave (c) is slower than the second compressional wave $(d)$.

In the snapshots, the waves will propagate as rings away from the source. Red and blue indicate positive and negative amplitudes, respectively. The stronger the color, the higher the amplitude. For this example the absolute value of the amplitude of the individual wave fields is only of subordinate relevance; no color bars are indicated. Higher wave velocities of the material will result in larger rings in the snapshots shown for a fixed elapsed time. At the air/ snow interface the air-pressure wave will be converted into a reflected air-pressure wave, transmitted first and second compressional waves, as well as a transmitted shear wave. The shear wave is not of interest here and cannot be seen in the presented snapshots. The first and second compressional waves will travel in the poroelastic material with its characteristic velocities. If this velocity is higher than that of the incident wave, the ring in the lower domain will be larger than that in the upper domain (Fig. 14a). If the velocity is less than the speed of sound in the air, the ring in the lower domain will be elliptic with a shorter vertical axis (Fig. 14b-d). Note the particularly short vertical axis in Figure 14c, which indicates an especially low velocity.

Due to the interaction between pore fluid and skeleton, a propagating wave mode will also have an amplitude in field variables that are not its main field variable. For light snow this interaction is relatively strong. Therefore in Figure 14c not only the strong amplitude of the slower first compressional wave with its short vertical axis can be seen, but also a 'shadow' of the faster second compressional wave that almost completes the circle of the air pressure wave in the upper domain. From Figure 14 it becomes clear that in the simulation of light snow the second compressional wave is faster than the first compressional wave.

\subsection{Increased sound absorption of light snow}

The attenuation levels of the first compressional wave differ

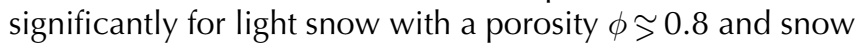
with a lower porosity. This separation corresponds roughly to a separation between freshly fallen and aged snow (Judson and Doesken, 2000). Between the two porosity ranges, the attenuation vanishes completely as the two wave modes have the same velocity and the viscous effects leading to attenuation are not in effect. The sound absorption above ground is a complex combination of effects involving, amongst others, the interference of incident and reflected waves, the reflection coefficient, geometrical spreading, as well as surface and non-geometrical waves (Embleton, 1996). However, it is clear that if the reflection coefficient of the ground decreases, the sound level above the ground also decreases (Watson, 1948; Nicolas and others, 1985). Due to the high porosity of snow and the open pore boundary conditions, the pressure of the air above the snowpack interacts mainly with the air in the pore space and little energy is transmitted into the ice frame. As the velocity of the second compressional wave is almost equal to the velocity of the air above the snow, there is almost no impedance contrast that would lead to a 
reflection. The low velocity of the first compressional wave in snow with porosity $\phi>0.8$ and the corresponding higher attenuation further decreases the impedance contrast and also reduces the contribution of refracted waves.

\section{CONCLUSIONS}

A method to predict phase velocities and plane wave attenuation of acoustic waves as a function of snow porosity has been presented. It is based on Biot's (1956a) model of wave propagation in porous materials and uses empirical relationships to assess tortuosity, permeability, bulk and shear moduli as a function of porosity. The properties of the ice frame of the snow and air as the pore fluid are assumed constant. The method is not restricted to porosity, as a single degree of freedom and additional information on SSA or any of the other properties characterizing a Biot-type porous material can be readily incorporated.

For light snow with a porosity $\phi \widetilde{>} 0.8$ the peculiarity is found that the velocities of the first compressional wave are slower than the phase velocities of the second compressional wave which is commonly referred to as the 'slow' wave. Such a reversal of the velocities of the compressional waves has been observed in reticulated foam before and is due to the weak structure of the ice matrix in fresh and light snow. The wave velocity reversal is a relatively sharp boundary for the attenuation level of the first compressional wave, which is orders of magnitude larger for highly porous snow. This finding is in accordance with the well-known observation that freshly fallen snow absorbs most of the ambient noise, while after a relatively short time this absorbing behavior vanishes.

The first compressional wave is sensitive mainly to matrix and shear bulk moduli. A variation of $\sim 25 \%$ in both shear and matrix bulk moduli can characterize the variability in measured velocities. The attenuation of the second compressional wave decreases with increasing porosity and is considerably higher than for the first compressional wave. Also frequency dependence of the attenuation is considerably more distinct for the second compressional wave. The velocity of the second compressional wave depends strongly on tortuosity, permeability and the related SSA. The variation of measured wave velocities for the second compressional wave can be obtained by altering the tortuosity by $\sim 30 \%$ or by altering the permeability by $\sim 50 \%$.

This method is a basic requirement for numerical modeling of acoustic wave propagation in snow, which makes it possible, for example, to assess the design of acoustic experiments to probe for snow properties or to assess the role of acoustic wave propagation in artificial or skier-triggered snow avalanche releases.

Further research will address the presence of liquid water in the pore space, a more complete analysis of sound absorption above snow of varying porosity, and numerical simulations of explosive avalanche mitigation experiments.

\section{ACKNOWLEDGEMENTS}

This research was founded by a fellowship of the Swiss National Science Foundation. I thank editors John Glen, Perry Bartelt, chief editor Jo Jacka, reviewer Henning Löwe and two anonymous reviewers for constructive comments and suggestions that helped to improve the manuscript.

\section{REFERENCES}

Albert DG (2001) Acoustic waveform inversion with application to seasonal snow covers. J. Acoust. Soc. Am., 109, 91-101 (doi: 10.1121/1.1328793)

Albert DG, Decato SN and Perron FE (2009) Experimental measurements of the Biot slow wave in natural snow covers. In Proceedings of the Fourth Biot Conference on Poromechanics. integrated PoroMechanics Institute, University of Oklahoma, Norman, OK, 724-729

Albert DG, Taherzadeh S, Attenborough K, Boulanger P and Decato SN (2013) Ground vibrations produced by surface and near-surface explosions. Appl. Acoust., 74(11), 1279-1296 (doi: 10.1016/j.apacoust.2013.03.006)

Attenborough $\mathrm{K}$ and Buser O (1988) On the application of rigidporous models to impedance data for snow. J. Sound Vibrat., 124(2), 315-327 (doi: 10.1016/S0022-460X(88)80190-1)

Attenborough K, Bashir I, Shin HC and Taherzadeh S (2012) Slow waves, surface waves and their applications. In Acoustics 2012. Société Française d'Acoustique, Nantes, 1877-1882

Attenborough K, Bashir I and Taherzadeh S (2013) Surface waves over rigid-porous and rough surfaces. J. Acoust. Soc. Am., 133(5), 3351-3351 (doi: 10.1121/1.4805688)

Bader H (1952) Preliminary investigations of some physical properties of snow. Engineering Experiment Station, Institute of Technology, University of Minnesota, Minneapolis, MN

Bear J (1972) Dynamics of fluids in porous media. American Elsevier, New York

Berryman JG (1980) Confirmation of Biot's theory. Appl. Phys. Lett., 37, 382-384 (doi: 10.1063/1.91951)

Biot MA (1956a) Theory of propagation of elastic waves in a fluidsaturated porous solid. I. Low-frequency range. J. Acoust. Soc. Am., 28, 168-178 (doi: 10.1121/1.1908239)

Biot MA (1956b) Theory of propagation of elastic waves in a fluidsaturated porous solid. II. Higher frequency range. J. Acoust. Soc. Am., 28, 179-191 (doi: 10.1121/1.1908241)

Biot MA (1962) Mechanics of deformation and acoustic propagation in porous media. J. Appl. Phys., 33, 1482-1498 (doi: 10.1063/1.1728759)

Bourbié T, Coussy O and Zinszner B (1987) Acoustics of porous media. Edition Technip, Paris

Buser O (1986) A rigid-frame model of porous media for the acoustic impedance of snow. J. Sound Vibrat., 111, 71-92 (doi: 10.1016/S0022-460X(86)81424-9)

Calonne $\mathrm{N}$ and 6 others (2012) 3-D image-based numerical computations of snow permeability: links to specific surface area, density, and microstructural anisotropy. Cryosphere, 6, 939-951 (doi: 10.5194/tc-6-939-2012)

Carcione JM (2007) Wave fields in real media: wave propagation in anisotropic, anelastic, porous and electromagnetic media, 2 nd edn. Elsevier, Amsterdam

Carcione JM and Picotti S (2006) P-wave seismic attenuation by slow-wave diffusion: effects of inhomogeneous rock properties. Geophysics, 71, O1-O8 (doi: 10.1190/1.2194512)

Darcy $\mathrm{H}$ (1856) Les fontaines publiques de la ville de Dijon. Dalmont, Paris

Deresiewicz H and Skalak R (1963) On uniqueness in dynamic poroelasticity. Bull. Seismol. Soc. Am., 53, 783-788

Domine F, Taillandier AS and Simpson WR (2007) A parameterization of the specific surface area of seasonal snow for field use and for models of snowpack evolution. J. Geophys. Res., 112, F02031 (doi: 10.1029/2006JF000512)

Embleton TF (1996) Tutorial on sound propagation outdoors. J. Acoust. Soc. Am., 100(1), 31-48 (doi: 10.1121/1.415879)

Fellah ZEA, Chapelon JY, Berger S, Lauriks W and Depollier C (2004) Ultrasonic wave propagation in human cancellous bone: application of Biot theory. J. Acoust. Soc. Am., 116(1), 61-73 (doi: 10.1121/1.1755239)

Garat J, Krief M, Stellingwerff J and Ventre J (1990) A petrophysical interpretation using the velocities of $\mathrm{P}$ and $\mathrm{S}$ waves (full waveform sonic). Log Analyst, 31, 355-369 
Geertsma J and Smit D (1961) Some aspects of elastic wave propagation in fluid-saturated porous solids. Geophysics, 26(2), 169-181 (doi: 10.1190/1.1438855)

Gubler H (1977) Artificial release of avalanches by explosives. J. Glaciol., 19, 419-429

Herbert B and 6 others (2005) Polychlorinated naphthalenes in air and snow in the Norwegian Arctic: a local source or an Eastern Arctic phenomenon? Sci. Total Environ., 342(1), 145-160 (doi: 10.1016/j.scitotenv.2004.12.029)

Hobbs PV (1974) Ice physics. Clarendon Press, Oxford

Hoffman JJ, Nelson AM, Holland MR and Miller JG (2012) Cancellous bone fast and slow waves obtained with Bayesian probability theory correlate with porosity from computed tomography. J. Acoust. Soc. Am., 132(3), 1830-1837 (doi: $10.1121 / 1.4739455)$

Jocker J and Smeulders D (2009) Ultrasonic measurements on poroelastic slabs: determination of reflection and transmission coefficients and processing for Biot input parameters. Ultrasonics, 49, 319-330 (doi: 10.1016/j.ultras.2008.10.006)

Johnson DL, Koplik J and Dashen R (1987) Theory of dynamic permeability and tortuosity in fluid-saturated porous media. J. Fluid Mech., 176, 379-402

Johnson JB (1982) On the application of Biot's theory to acoustic wave propagation in snow. Cold Reg. Sci. Technol., 6, 49-60 (doi: 10.1016/0165-232X(82)90044-1)

Judson A and Doesken N (2000) Density of freshly fallen snow in the central Rocky Mountains. Bull. Am. Meteorol. Soc., 81(7), 1577-1587 (doi: 10.1175/1520-0477(2000)081<1577:DOFF$\mathrm{SI}>2.3 . \mathrm{CO} ; 2)$

Kapil J, Datt P, Kumar A, Singh K, Kumar V and Satyawali P (2014) Multi-sensor couplers and waveguides for efficient detection of acoustic emission behavior of snow. Cold Reg. Sci. Technol., 101, 1-13 (doi: 10.1016/j.coldregions.2014.01.003)

Kinar NJ and Pomeroy JW (2009) Automated determination of snow water equivalent by acoustic reflectometry. IEEE Trans. Geosci. Remote Sens., 47, 3161-3167 (doi: 10.1109/TGRS.2009. 2019730)

Lacroix P and 6 others (2012) Monitoring of snow avalanches using a seismic array: location, speed estimation, and relationships to meteorological variables. J. Geophys. Res., 117(F1), F01034 (doi: 10.1029/2011JF002106)

Legagneux L, Cabanes A and Dominé F (2002) Measurement of the specific surface area of 176 snow samples using methane adsorption at 77 K. J. Geophys. Res., 107(D17), 4335 (doi: 10.1029/2001JD001016)

Lide DR (2005) CRC handbook of chemistry and physics, 86th edn. CRC Press, Boca Raton, FL

Marco O, Buser O and Villemain P (1996) Analysis of a rigid frame model of porous media for the acoustic properties of dense snow. J. Sound Vibrat., 196, 439-451 (doi: 10.1006/ jsvi.1996.0494)

Marco O, Buser O, Villemain P, Touvier F and Revol H (1998) Acoustic impedance measurement of snow density. Ann. Glaciol., 26, 92-96

Mavko G and Nur A (1997) The effect of a percolation threshold in the Kozeny-Carman relation. Geophysics, 62(5), 1480-1482 (doi: 10.1190/1.1444251)

Mavko G, Mukerji T and Dvorkin J (2009) The rock physics handbook: tools for seismic analysis in porous media, 2nd edn. Cambridge University Press, Cambridge

Maysenhölder W, Heggli M, Zhou X, Zhang T, Frei E and Schneebeli M (2012) Microstructure and sound absorption of snow. Cold Reg. Sci. Technol., 83, 3-12 (doi: 10.1016/ j.coldregions.2012.05.001)

Mellor M (1975) A review of basic snow mechanics. IAHS Publ. 114 (Symposium at Grindelwald 1974 - Snow Mechanics), 251-291
Mellor M (1983) Mechanical behavior of sea ice. CRREL Monogr. 83-1

Nicolas J, Berry JL and Daigle G (1985) Propagation of sound above a finite layer of snow. J. Acoust. Soc. Am., 77(1), 67-73 (doi: 10.1121/1.391902)

O'Connell R and Budiansky B (1978) Measures of dissipation in viscoelastic media. Geophys. Res. Lett., 5(1), 5-8 (doi: 10.1029/ GL005i001p00005)

Oura H (1952) Reflection of sound at snow surface and mechanism of sound propagation in snow. Low Temp. Sci., 9, 179-186

Pride SR (2005) Relationships between seismic and hydrological properties. In Hydrogeophysics. Springer, Berlin, 253-291

Reuter B, Proksch M, Loewe H, Van Herwijnen A and Schweizer J (2013) On how to measure snow mechanical properties relevant to slab avalanche release. In Proceedings of the International Snow Science Workshop, 7-11 October 2013, Grenoble, France. International Snow Science Workshop, 7-11

Roch A (1948) Discussion sur la valeur du nombre de Poisson $\mathrm{m}$ pour la neige, Davos Weissfluhjoch. Eidg. Inst. SchneeLawinenforsch. Interner Ber. 89

Schneebeli M (2004) Numerical simulation of elastic stress in the microstructure of snow. Ann. Glaciol., 38, 339-342 (doi: 10.3189/172756404781815284)

Schulson EM (1999) The structure and mechanical behavior of ice. JOM J. Mineral. Metal. Mater. Soc., 51, 21-27

Shapiro LH, Johnson JB, Sturm M and Blaisdell GL (1997) Snow mechanics: review of the state of knowledge and applications. CRREL Tech. Rep. 97.3

Shin HC, Taherzadeh S, Attenborough K, Whalley W and Watts C (2013) Non-invasive characterization of pore-related and elastic properties of soils in linear Biot-Stoll theory using acoustic-toseismic coupling. Eur. J. Soil Sci., 64(3), 308-323 (doi: 10.1111/ ejss.12000)

Sidler R, Carcione JM and Holliger K (2010) Simulation of surface waves in porous media. Geophys. J. Int., 183, 820-832 (doi: 10.1111/j.1365-246X.2010.04725.x)

Smeulders DMJ (2005) Experimental evidence for slow compressional waves. J. Eng. Mech., 31, 908-917 (doi: 10.1061/(ASCE) 0733-9399(2005)131:9(908))

Smith N (1969) Determining the dynamic properties of snow and ice by forced vibration. (Technical report) Defense Technical Information Center, US Department of Defense, Cameron Station, Alexandria, VA

Sommerfeld R (1982) A review of snow acoustics. Rev. Geophys., 20(1), 62-66 (doi: 10.1029/RG020i001p00062)

Sommerfeld R and Gubler H (1983) Snow avalanches and acoustic emissions. Ann. Glaciol, 4, 271-276

Surinach E, Sabot F, Furdada G and Vilaplana J (2000) Study of seismic signals of artificially released snow avalanches for monitoring purposes. Phys. Chem. Earth B, 25(9), 721-727 (doi: 10.1016/S1464-1909(00)00092-7)

Terzaghi K (1923) Die Berechnung der Durchlässigkeitsziffer des Tones aus dem Verlauf der hydrodynamischen Spannungserscheinungen. Akad. Wiss. Wien Math.-Naturwiss. Kl. Sitzungber., 132, 125-138

Van Herwijnen A and Schweizer J (2011) Monitoring avalanche activity using a seismic sensor. Cold Reg. Sci. Technol., 69(2), 165-176 (doi: 10.1016/j.coldregions.2011.06.008)

Watson RB (1948) On the propagation of sound over snow. J. Acoust. Soc. Am., 20(6), 846-848 (doi: 10.1121/1.1906447)

Yamada T, Hasemi T, Izumi K and Sato A (1974) On the dependencies of the velocities of $\mathrm{P}$-and $\mathrm{S}$-waves and thermal conductivity of snow upon the texture of snow. Contrib. Inst. Low Temp. Sci., 32, 71-80

Zwikker C and Kosten C (1947) Sound absorbing materials. Elsevier, Amsterdam 